\title{
Arabic translation and validation of the Sinus and Nasal Quality of Life Survey (SN- 5 ) in pediatric patients with chronic rhinosinusitis
}

\author{
Ahmed A. Ragab ${ }^{1}$, Zeinab A. Kasemy ${ }^{2}$ and Ahmad M. Hamdan ${ }^{1 *}$ (D)
}

\begin{abstract}
Background: This study aimed to validate the translation of the Sinus and Nasal Quality of Life Survey (SN-5) into Arabic (SN-5a) in pediatric chronic rhinosinusitis (CRS) patients. A prospective cohort randomized controlled study was conducted on 129 children with CRS and 100 age- and sex-matched healthy children. The questionnaire was translated into the Arabic language with cross-cultural adaptation. Caregivers answered the questionnaire during their first visits and after 1 week; to assess test-retest reliability and after 2 weeks of medical treatment to test the questionnaire's ability to detect changes in patients' symptoms. The responses of the patients and control groups were compared to assess the external validity.
\end{abstract}

Results: The SN-5a showed internal consistency and reliability, with Cronbach's alpha value being 0.69. Item-item and item-total correlation analysis showed adequate construct validity with a highly significant negative correlation between the SN-5 questionnaire items and visual analog scale (VAS) $(p<0.001)$. There were highly significant positive correlations between items of the questionnaire in the 1 st and 2 nd visits at 1 week $(p<0.001)$. A highly significant difference between the case and control groups had been shown for all SN-5a items $(p<0.001)$. Two weeks after treatment, there were large changes in all the questionnaire items between the first and last visits (effect size $>0.8$ for all).

Conclusion: The translated SN-5a exhibited adequate construct validity, internal consistency, test-retest reliability, and external validity with quite enough ability to assess the longitudinal changes of the disease.

Keywords: Arabic translation, Cross-cultural adaptation, Pediatric chronic rhinosinusitis, Quality of life, Sinus and Nasal Quality of Life Survey

\section{Background}

Rhinosinusitis is common in the pediatric age group, the acute form of the disease can affect $7-12 \%$ of children [1], while chronic rhinosinusitis CRS had a prevalence between 1.5 and $2.1 \%[2,3]$. According to the recent European Position Paper on Rhinosinusitis and Nasal Polyps 2020 (EPOS) [4], CRS's cardinal symptoms

\footnotetext{
* Correspondence: Ahmed.Hamdan@med.menofia.edu.eg

'Otolaryngology Head \& Neck Surgery Department, Faculty of Medicine,

Menoufia University, Shebin El-kom, Egypt

Full list of author information is available at the end of the article
}

include nasal congestion, facial pain, nasal obstruction, anterior or posterior nasal discharge, and smell disorder. In addition to nasal symptoms, both acute and chronic pediatric rhinosinusitis have significant impacts on the quality of life (QoL) of children, manifested mainly as body aches and restriction of school and social activities [1]. One of the important treatment goals is to improve QoL in such children by applying QoL questionnaires to treated children. The QoL questionnaires help measure clinical presentation changes over time with a certain treatment line to assess this treatment's efficacy and the 
possible need for a different treatment line [5]. Several questionnaires were developed to measure the overall quality of life in pediatric patients, such as the Autoquestionnaire de Qualité de Vie Enfant Imagé (AUQEI) [6]. However, these questionnaires are generalized and do not allow assessment of a specific disease entity. While QoL questionnaires for adult CRS have limited standardization due to various QoL assessment tools, QoL questionnaires for pediatric CRS are limited and scarce. Up to the present time, the only validated pediatric CRS outcome tool is the SN-5. A published study in 2003 succeeded in attaining validation, test-retest reliability, construct validity, and internal consistency of SN-5 [7]. Since its validation, this questionnaire has been used in different studies related to pediatric CRS (e.g., epidemiological analysis [8], medical management using nasal saline irrigation [9], and surgical treatment using balloon catheter sinuplasty [10], adenoidectomy [10], and endoscopic sinus surgery [11, 12]). According to a recent systematic review, limited ten publications provided assessment of interventions in pediatric CRS using SN-5 QoL questionnaires [13]. Translation and validation of SN-5 can allow more and widespread use of such a short, straightforward, and easily administered QoL questionnaire in pediatric rhinosinusitis studies. To the best of our knowledge, translation of SN-5 into Arabic and its validation was not done before. The present study aimed to validate the translation with a cross-cultural adaptation of the Sinus and Nasal Quality of Life Survey (SN-5) into Arabic (SN-5a) in CRS pediatric patients.

\section{Methods}

This prospective cohort randomized, controlled study was conducted at an otorhinolaryngology center during the period from March 2020 to December 2020 on 129 children. The parents of children who met the following inclusion criteria were asked to participate in the study: (a) a child age was 2-12 years, (b) children had chronic rhinosinusitis according to EPOS 2020 [4] (e.g., two CRS symptoms including nasal obstruction and/or discolored discharge \pm facial pain/pressure \pm reduction or loss of smell, for more than 12 weeks. Children with the following diseases were excluded: a delay in developmental milestones, cognitive impairment, and any genetic disorders. Also, children with other otorhinolaryngology diseases were excluded (e.g., obstructive sleep apnea syndrome (OSAS), primary ciliary dyskinesia, cystic fibrosis, paranasal sinus fungal diseases, nasal granulomas, and sinonasal tumors).

\section{Ethical approval}

Approval was obtained from Institutional Review Boards (IRB) of the Menoufia Faculty of Medicine under the number 3-2020 ENT, and following the Declaration of Helsinki. After an explanation of all aspects of the study and giving the right to withdraw at any time, written consent was taken from all the children's legal guardians.

\section{Sample size}

A sample size of 123 subjects was required to perceive a population correlation as small as 0.30 and estimate test-retest reliability within 0.05 [14]. Accounting for a dropout of $10 \%$ sample size had been increased to 137 participants. One hundred and thirty-five participants agreed to participate, giving a response rate of $98.5 \%$, out of which, 129 patients completed the study fulfilling the three visits of the study.

\section{Control group}

The study included 100 age- and sex-matched normal subjects not diagnosed as having chronic rhinosinusitis and recruited from the Otorhinolaryngology department's outpatient clinic.

\section{Questionnaire}

The SN-5 questionnaire (Fig. 1) consists of a group of five questions that the parents of the children should answer. Each question is scored on a seven-point scale intended to quantify the frequency of symptoms over the previous month. The questionnaire assesses nasal obstruction symptoms, sinus infection, allergy symptoms, restrictions of activity, and emotional distress. A visual analog scale (VAS) from 0 to 10 was used to measure the overall quality of life [7].

\section{Cross-cultural adaptation}

The cross-cultural adaptation process followed the guidelines proposed by Guillemin et al. [15] and Ruperto et al. [16], which comprised six stages: (a) Stage I: initial translation into the Arabic language by two independent translators with Arabic being their native language (One of them was briefed about the aim and concepts of the questionnaire and had a clinical background.); (b) Stage II: blended translations by integrating the two translations (conducted by the two translators) into one common translation, with a written report documenting this process; (c) Stage III: back translation of the Arabic format back into English by two translators who were neither aware nor informed of the questionnaire's concepts and without a medical background; (d) Stage IV: expert committee including methodologists, Otorhinolaryngologists, language professionals, and the translators (forward and back translators), integrated all the versions of the questionnaire and developed the prefinal version of the questionnaire for field testing; (e) Stage V: an appraisal of the Arabic forms and back translations; (f) 
Instructions: Please help us understand the impact of sinus and/or nasal problems on your child's quality of life by checking one box $[\mathrm{x}]$ for each question below. Thank you.

SINUS INFECTION: Nasal discharge, bad breath, daytime cough, post-nasal drip, headache, facial pain or head banging. How often a problem for your child during the past 4 weeks?
[1] None of the time
1 Hardly any time at all
I A small part of the time
I Some of the time
(1) A good part of the time
I. Most of the time

NASAL OBSTRUCTION: Stuffy or blocked nose, nasal congestion, reduced sense of smell, trouble breathing with mouth closed. How often a problem for your child during the past 4 weeks?
[ ] None of the time
I I Hardly any time at all
[1] A good part of the time
i) Some of the time
I Alst of the time

ALLERGY SYMPTOMS: Sneezing, itchy nose/eyes, need to rub nose/eyes, or watery eyes. How often a problem for your child during the past 4 weeks?
( ) None of the time
1 Hardly any time at all
1) A small part of the time
1) A good part of the time
[1] Most of the time
II All of the time

ENoTIONAL DISTRESS: Irritable, frustrated, sad, restless, or trouble sleeping. How often a problem for your child during the past 4 weeks because of nose or sinus illness?
(1) None of the time
1) Hardly any time at all
if A small part of the time
if some of the time
[1] A good part of the time
(1) Most of the time
if All of the time

ACTIVITY LIMITATIONS: Missed school/daycare, lost time with family/friends, unable to do projects. How often a problem for your child during the past 4 weeks because of nose or sinus illness?
( ) None of the time
if Hardly any timo at all
[1] A good part of the time
1 S Some of the time
I 1 All of the time

OVERALL, HOW WOULO YOU RATE YOUR CHILO'S QUALTYY OF LIFE AS A RESULT OF NOSE OR SINUS PROBLEMS? (Circle one number)

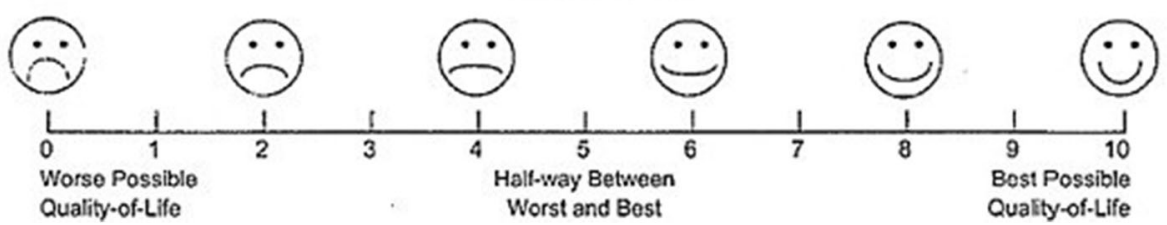

Fig. 1 The English version of "The Sinus and Nasal Quality of Life Survey" (SN-5)

Stage VI: development of the SN-5a final questionnaire. The final Arabic version was used in a pilot study on ten patients to assess its clarity. The legal guardians of eligible participants answered the Arabic SN-5 questionnaire during their clinical visits, and after 1 week to assess test-retest reliability. Patients received medical treatment, including nasal saline lavage and oral antibiotics (amoxicillin/clavulanic acid) for 14 days. SN-5 was readministered after 2 weeks of treatment to test the questionnaire's ability to detect changes in patients' symptoms over time or after treatment.

\section{Statistical analysis}

Results were statistically evaluated by SPSS version 22 (SPSS Inc., Chicago, IL, USA). Internal consistency reliability was assessed by calculating Cronbach's alpha and inter-item and item-total correlations and was satisfactory if $>0.70$. Test-retest reliability of the SN-5a questionnaire was evaluated using Spearman's correlation coefficient, correlating responses to the initial questionnaire with the questionnaire's responses after 1 week to detect patients who did not exhibit any change in the questionnaire response. The effect size was calculated for alteration levels using the standardized response mean (SRM) by dividing the mean $\mathrm{SN}-5$ a change score by its standard deviation. SRM of about 0.20 is taken as a small change, SRM of 0.50 ( moderate change) and SRM of at least 0.80 (large change). A $p$ value $<0.05$ was considered significant, and a $p$ value $<0.001$ was considered highly significant.

\section{Results}

The current study included 135 children, out of which, 129 children completed the study in all three visits. These 129 patients included 74 males (57.3\%) and 55 females $(42.7 \%)$; their mean age of the study group was 6.8 years \pm 2.10 . The control group included 100 children distributed as 68 males $(68 \%)$ and 32 females $(32$ 
Table 1 Age and sex of the studied groups

\begin{tabular}{|c|c|c|c|c|c|c|}
\hline & \multicolumn{2}{|c|}{$\begin{array}{l}\text { Patients } \\
(n=129)\end{array}$} & \multicolumn{2}{|c|}{$\begin{array}{l}\text { Controls } \\
(n=100)\end{array}$} & \multirow[t]{2}{*}{ Test of sig } & \multirow[t]{2}{*}{$\begin{array}{l}p \\
\text { value }\end{array}$} \\
\hline & No. & Percent & No. & Percent & & \\
\hline \multicolumn{7}{|l|}{ Sex } \\
\hline Male & 74 & 57.3 & 68 & 68 & $x^{2}=2.704$ & 0.1 \\
\hline Female & 55 & 42.7 & 32 & 32 & & \\
\hline \multicolumn{7}{|l|}{ Age (years) } \\
\hline Mean \pm SD & \multicolumn{2}{|c|}{$6.8 \pm 2.10$} & \multicolumn{2}{|c|}{$7.19 \pm 1.57$} & $t=-1.561$ & 0.12 \\
\hline
\end{tabular}

\%) with a mean age of 7.19 years \pm 1.57 . There was a non-significant difference between the two groups concerning age and sex $(p=0.12$ and 0.1 , respectively) (Table 1). The questionnaire showed that all items shared quite enough internal consistency and exhibited good reliability, with Cronbach's alpha value being 0.69. Item-item and item-total correlation assessment displayed adequate construct validity with a highly significant negative correlation between items of the $\mathrm{SN}-5 \mathrm{a}$ questionnaire and VAS ( $r$ for total score $=-0.846, p<$ 0.001) (Table 2). Regarding test-retest reliability, there was a highly significant positive correlation between items of the SN-5a questionnaire in the 1st and 2nd visits at 1 week $(p<0.001)$ (Table 3$)$. Regarding the external validity, there was a significant difference between the case and control groups regarding all items of the SN5a questionnaire $(p<0.001)$ (Table 4). Regarding sensitivity to longitudinal change, there was a large change in all the questionnaire items between the first and last visits at 2 weeks after treatment (effect size $>0.8)($ Table 5).

\section{Discussion}

The development of a tool to measure pediatric patients' quality of life represents a major challenge to physicians due to the target population's unique character. Children cannot properly express their wellbeing and find themselves depending on their caregivers and their perception about children's quality of life. The caregivers' concepts and attitudes may bias such
Table 3 Test-retest reliability of the SN-5 questionnaire at the 1 st and 2 nd visits

\begin{tabular}{lllll}
\hline SN-5 & \multicolumn{2}{l}{ Patients $(\boldsymbol{N}=\mathbf{1 2 9})$} & $\begin{array}{l}\text { Spearman's } \\
\text { correlation }\end{array}$ & $\boldsymbol{p}$ value \\
\cline { 2 - 3 } & 1st visit & 2nd visit & & \\
\hline Mean \pm SD & Mean \pm SD & & \\
\hline Q1 & $3.12 \pm 1.37$ & $3.18 \pm 1.32$ & 0.977 & $<0.00001^{* *}$ \\
M (IQR) & $3(2-4)$ & $3(2-4)$ & & \\
Q2 & $3.71 \pm 1.30$ & $3.73 \pm 1.26$ & 0.991 & $<0.00001^{* *}$ \\
M(IQR) & $4(3-5)$ & $4(3-5)$ & & \\
Q3 & $3.34 \pm 1.09$ & $3.36 \pm 1.07$ & 0.986 & $<0.00001^{* *}$ \\
M(IQR) & $3(3-4)$ & $3(3-4))$ & & \\
Q4 & $2.76 \pm 1.17$ & $2.78 \pm 1.15$ & 0.994 & $<0.00001^{* *}$ \\
M(IQR) & $3(2-3)$ & $3(2-3)$ & & \\
Q5 & $2.17 \pm 0.99$ & $2.23 \pm 0.98$ & 0.971 & $<0.00001^{* *}$ \\
M(IQR) & $2(1-3)$ & $2(1-3)$ & & \\
Total score & $15.1 \pm 3.97$ & $15.28 \pm 3.85$ & 0.990 & $<0.00001^{* *}$ \\
M(IQR) & $15(12-18)$ & $15(13-18)$ & & \\
VAS & $5.38 \pm 1.32$ & $5.46 \pm 1.28$ & 0.979 & $<0.00001^{* *}$ \\
M(IQR) & $5(5-6)$ & $5(5-6)$ & & \\
\hline
\end{tabular}

** Highly significant, $M$ median, IQR interquartile range

perception. This bias poses the need for a quality of life questionnaire with comprehensible questions without confusion in intelligibility [17].

An ideal health-related quality of life questionnaire should be comprehensive and easily intelligible with easy administration. It should be able to measure changes in the clinical picture over time or with treatment. The questionnaire results should be stable without significant change on readministration, which is known as a test to test reliability. The questionnaire items should measure various aspects of the same health disorder, known as internal consistency. However, construct validity remains a major requirement in any survey for quality of life measurement, which means the survey's ability to measure what it is intended to measure [18].

The present Arabic validation SN-5a allowed easy, direct measurement of QoL changes and assessment of improvement in CRS after medical treatment. In a recent systematic review [13], although there were an overall scarcity of data using QoL questionnaire for assessment of treatments in pediatric CRS, SN-5 provided an

Table 2 Construct validity and internal consistency of the SN-5 questionnaire

\begin{tabular}{|c|c|c|c|c|}
\hline \multirow[t]{2}{*}{$\begin{array}{l}\mathrm{SN}-5 \\
\text { questionnaire }\end{array}$} & \multicolumn{2}{|c|}{$\begin{array}{l}\text { Spearman's correlations between the SN-5 question- } \\
\text { naire and VAS score }\end{array}$} & \multicolumn{2}{|c|}{ Internal consistency of SN-5 questionnaire } \\
\hline & $R$ & $p$ value & Corrected item-total correlation & Cronbach's alpha if item deleted \\
\hline Q1 & -0.633 & $<0.001^{* *}$ & 0.556 & 0.585 \\
\hline Q2 & -0.441 & $<0.001^{* *}$ & 0.161 & 0.763 \\
\hline Q3 & -0.327 & $<0.001^{* *}$ & 0.248 & 0.713 \\
\hline Q4 & -0.722 & $<0.001^{* *}$ & 0.698 & 0.523 \\
\hline Q5 & -0.731 & $<0.001^{* *}$ & 0.683 & 0.554 \\
\hline Total score & -0.846 & $<0.001^{*}$ & Cronbach's alpha & 0.69 \\
\hline
\end{tabular}


Table 4 Comparison between controls and patients regarding $\mathrm{SN}-5$ questionnaire

\begin{tabular}{lllll}
\hline SN-5 & Groups & $\begin{array}{l}\text { Mann- } \\
\text { Whitney }\end{array}$ & $p$ value \\
\cline { 2 - 4 } & $\begin{array}{llll}\text { Patients (129) } \\
\text { Mean } \pm \text { SD }\end{array}$ & $\begin{array}{l}\text { Meantrols } \pm \text { SD } \\
\text { (100) }\end{array}$ & & \\
\hline Q1 & $3.12 \pm 1.37$ & $0.57 \pm 0.5$ & 12.168 & $<0.00001^{* *}$ \\
M(IQR) & $3(2-4)$ & $1(0-1)$ & & \\
Q2 & $3.71 \pm 1.30$ & $0.66 \pm 0.62$ & 12.253 & $<0.00001^{* *}$ \\
M(IQR) & $4(3-5)$ & $1(0-1)$ & & \\
Q3 & $3.34 \pm 1.09$ & $0.43 \pm 0.5$ & 12.841 & $<0.00001^{* *}$ \\
M(IQR) & $3(3-4)$ & $0(0-1)$ & & \\
Q4 & $2.76 \pm 1.17$ & $0.43 \pm 0.5$ & 12.106 & $<0.00001^{* *}$ \\
M(IQR) & $3(2-3)$ & $0(0-1)$ & & \\
Q5 & $2.17 \pm 0.99$ & $1.07 \pm 0.46$ & 8.038 & $<0.00001^{* *}$ \\
M(IQR) & $2(1-3)$ & $1(1-1)$ & & \\
Total score & $15.1 \pm 3.97$ & $3.16 \pm 1.31$ & 12.971 & $<0.00001^{* *}$ \\
M(IQR) & $15(12-18)$ & $3(2-4)$ & & \\
VAS & $5.38 \pm 1.32$ & $8.71 \pm 0.701$ & -12.75434. & $<0.00001^{* *}$ \\
M(IQR) & $5(5-6)$ & $9(8-9)$ & & \\
\hline
\end{tabular}

** Highly significant, $M$ median, IQR interquartile range

independent measurement of CRS QoL changes in children with quantitative assessment of improvement.

In the current study, all items of the SN5 questionnaire shared quite enough in the internal consistency of the questionnaire with fair Arabic translation reliability (Cronbach's alpha 0.69). Kay and Rosenfeld [7], in their development of the SN5 questionnaire, deleted the medication use because of low Cronbach's alpha (0.56) and an undesirable item-total correlation less than (0.20) in comparison with the other 5 QoL questionnaire items. Therefore, the survey was given a new name, SN5. Calvo-Henríquez et al. [19], in their cross-cultural adaptation to Spanish, found that the internal consistency of the Sp-SN-5 (evaluated with Cronbach's

Table 5 Sensitivity to longitudinal change of the SN-5 questionnaire in the 1st and last visits

\begin{tabular}{|c|c|c|c|c|}
\hline \multirow[t]{3}{*}{ SN-5 } & \multicolumn{2}{|c|}{ Patients $(N=129)$} & \multirow[t]{3}{*}{ Change } & \multirow{3}{*}{$\begin{array}{l}\text { Effect } \\
\text { size }\end{array}$} \\
\hline & 1st visit & Last visit & & \\
\hline & Mean $\pm S D$ & Mean $\pm S D$ & & \\
\hline $\begin{array}{l}\text { Q1 } \\
\text { M(IQR) }\end{array}$ & $\begin{array}{l}3.12 \pm 1.37 \\
3(2-4)\end{array}$ & $\begin{array}{l}2.05 \pm 1.36 \\
2(1-3)\end{array}$ & $\begin{array}{l}1.06 \pm 1.02 \\
1(0-2)\end{array}$ & 1.04 \\
\hline $\begin{array}{l}\text { Q2 } \\
M(I Q R)\end{array}$ & $\begin{array}{l}3.71 \pm 1.30 \\
4(3-5)\end{array}$ & $\begin{array}{l}2.19 \pm 1.1 \\
2(1-3)\end{array}$ & $\begin{array}{l}1.53 \pm 1.22 \\
2(0-2)\end{array}$ & 1.25 \\
\hline $\begin{array}{l}\text { Q3 } \\
M(I Q R)\end{array}$ & $\begin{array}{l}3.34 \pm 1.09 \\
3(3-4)\end{array}$ & $\begin{array}{l}2.11 \pm 1.4 \\
2(1-3)\end{array}$ & $\begin{array}{l}1.23 \pm 1.11 \\
1(0-2)\end{array}$ & 1.11 \\
\hline $\begin{array}{l}\text { Q4 } \\
M(I Q R)\end{array}$ & $\begin{array}{l}2.76 \pm 1.17 \\
3(2-3)\end{array}$ & $\begin{array}{l}1.58 \pm 1.18 \\
1(1-2)\end{array}$ & $\begin{array}{l}1.18 \pm 1.11 \\
1(0-2)\end{array}$ & 1.06 \\
\hline $\begin{array}{l}\text { Q5 } \\
M(I Q R)\end{array}$ & $\begin{array}{l}2.17 \pm 0.99 \\
2(1-3)\end{array}$ & $\begin{array}{l}1.2 \pm 079 \\
1(1-1)\end{array}$ & $\begin{array}{l}0.97 \pm 0.96 \\
1(0-2)\end{array}$ & 1.01 \\
\hline $\begin{array}{l}\text { Total score } \\
M(I Q R)\end{array}$ & $\begin{array}{l}15.1 \pm 3.97 \\
15(12-18)\end{array}$ & $\begin{array}{l}9.13 \pm 4.6 \\
8(5-13)\end{array}$ & $\begin{array}{l}5.97 \pm 4.59 \\
8(0-10)\end{array}$ & 1.3 \\
\hline
\end{tabular}

$M$ median, $I Q R$ interquartile range $\alpha)$ was high (0.87) for the five main domains of the questionnaire. Also, the internal consistency was still over 0.83 after removing each element of the test. Uchoa et al. [17], in their cross-cultural adaptation to Brazilian Portuguese, found the internal consistency of the SN-5p as 0.73 .

In the current study, there was a highly significant negative correlation between items of the SN-5 questions and VAS. Also in cross-cultural adaptation to Spanish [19], the authors found a strong negative correlation between the total result of the SN-5 items and the VAS in the general sample. Similarly, a significant correlation existed between $\mathrm{SN}-5 \mathrm{p}$ and the VAS in crosscultural adaptation to Brazilian Portuguese [17].

Regarding test-retest reliability in the present study, there was a highly significant positive correlation between items of the SN-5 questions in the 1st and 2nd visits at 1 week. Kay and Rosenfeld [7] identified that test-retest reliability for each individual item was fair to good. The overall questionnaire score had good test-retest reliability (correlations $>0.70$ ). In cross-cultural adaptation to Spanish [19], the study authors revealed a very high test-retest reliability with the intraclass correlation coefficient (ICC) of 0.94 for test-retest measurements. In cross-cultural adaptation to Brazilian [17], the investigators found the test-retest reproducibility 7 days after the primary interview as adequate $(r=0.957)$.

In the existing study, there was a highly significant difference between case and control groups regarding all items of the SN5a questionnaire. The Spanish authors in their cross-cultural adaptation to their language [19] found significant differences between the means in cases and controls in all the items of the test. The discriminant validity was statistically significant in the Brazilian Portuguese translation when assessing the difference in SN-5 scores between the studied and the control groups [17].

In the current study, there was a large change in all the questionnaire items between the first and last visit (4 weeks after treatment). The first authors to validate SN5 [7] reported that this questionnaire had outstanding sensitivity to alteration compared with other outcome measures. Change scores for the present questionnaire exhibited big changes relative to baseline with a large effect size. They found that the "sinus infection" and "nasal obstruction" questions were most sensitive to change, but all items had at least a small effect size. In Brazilian cultural adaptation [17], the authors found a significant improvement in all symptoms after receiving the planned medications with major changes in questionnaire scores between the first visit and 1 month visit which indicates that the SN-5 could quantify the clinical improvement.

The strengths of this study are that it is the first study to translate the SN5 questionnaire into Arabic, providing a tool to measure the magnitude of the problem of pediatric 
chronic rhinosinusitis and its impact on the quality of life of children in Arabic countries, which are known to have variable socioeconomic levels and health care levels. Such a tool will allow its future use in different studies about pediatric CRS in these countries concerning the epidemiology and effect of treatment approaches.

\section{Conclusion}

The SN-5 was effectively translated and cross-culturally adapted into the Arabic language, and the translated Arabic version showed adequate construct validity, internal consistency, test-retest reliability, external validity with quite enough ability to assess longitudinal change. The questionnaire effectively assessed the chronic rhinosinusitis patients' quality of life and can be used for this aim both in the clinical situations and in related research.

\begin{abstract}
Abbreviations
AUQEl: Autoquestionnaire de Qualité de Vie Enfant Imagé; CRS: Chronic rhinosinusitis; EPOS: European Position Paper on Rhinosinusitis and Nasal Polyps; ICC: Intraclass correlation coefficient; IRB: Institutional review board; QoL: Quality of life; SN-5: Sinus and Nasal Quality of Life Survey; SN-5a: Arabic Sinus and Nasal Quality of Life Survey (SN-5); SRM: Standardized response mean; VAS: Visual analog scale
\end{abstract}

\section{Acknowledgment}

The authors acknowledge and appreciate the role of the forward and back translators of the questionnaire and other members of the expert committee who integrated all the versions of the questionnaire and developed the prefinal version of the questionnaire for field testing.

\section{Authors' contributions}

AR provided the concept, design with the definition of the intellectual content, data analysis, and manuscript editing. ZK conducted literature research, clinical studies, data collection, and data analysis. AH conducted clinical studies, data collection, data analysis, and manuscript preparation. The authors read and approved the final manuscript.

\section{Funding}

There was no funding for this research.

\section{Availability of data and materials}

The datasets used and/or analyzed during the current study are available from the corresponding author on reasonable request.

\section{Declarations}

Ethics approval and consent to participate

Approval was obtained from the Institutional Review Boards (IRB) of the Menoufia Faculty of Medicine under the number 3-2020 ENT and following the Declaration of Helsinki. After an explanation of all aspects of the study and giving the right to withdraw at any time, written consent was taken from all the children's legal guardians..

\section{Consent for publication}

Not applicable

\section{Competing interests}

No potential competing interests relevant to this article was reported for any of the authors.

\section{Author details}

'Otolaryngology Head \& Neck Surgery Department, Faculty of Medicine, Menoufia University, Shebin El-kom, Egypt. ${ }^{2}$ Public Health and Community Medicine Department, Faculty of Medicine Menoufia University Shebin El-kom Egypt
Received: 17 March 2021 Accepted: 28 May 2021

Published online: 28 July 2021

\section{References}

1. Kennedy AA, Gerber ME (2020) Burden and health impact of pediatric rhinosinusitis. In: Ramadan H, Baroody F (eds) Pediatric Rhinosinusitis. Springer, Cham, pp 9-15. https://doi.org/10.1007/978-3-030-22891-0_2

2. Gilani S, Shin JJ (2017) The burden and visit prevalence of pediatric chronic rhinosinusitis. Otolaryngol Head Neck Surg 157(6):1048-1052. https://doi. org/10.1177/0194599817721177

3. Westman M, Stjärne P, Bergström A, Kull I, Toskala E, Cardell LO, Wickman M, Holmström M (2015) Chronic rhinosinusitis is rare but bothersome in adolescents from a Swedish population-based cohort. J Allergy Clin Immunol 136:512-4.e6

4. Fokkens WJ, Lund VJ, Hopkins C et al (2020) European position paper on rhinosinusitis and nasal polyps 2020. Rhinology 58(1):1-464. https://doi. org/10.4193/Rhin20.401

5. Adams PF, Hendershot GE, Marano MA (1999) Current estimates from the National Health Interview Survey, 1996. Vital Health Stat 10:1-203

6. Assumpção FB, Kuczynski E, Sprovieri MH, Aranha EM (2000) Quality of life evaluation scale (AUQEI--Autoquestionnaire Qualité de Vie Enfant Imagé). Validity and reliability of a quality of life scale for children 4 to 12 years-old. Arq Neuropsiquiatr 58(1):119-127. https:/doi.org/10.1590/s0004-282x2000000100018

7. Kay DJ, Rosenfeld RM (2003) Quality of life for children with persistent sinonasal symptoms. Otolaryngol Head Neck Surg 128(1):17-26. https://doi. org/10.1067/mhn.2003.41

8. Erwin EA, Faust RA, Platts-Mills TA, Borish L (2011) Epidemiological analysis of chronic rhinitis in pediatric patients. Am J Rhinol Allergy 125:327-332

9. Wei JL, Sykes KJ, Johnson P, He J, Mayo MS (2011) Safety and efficacy of oncedaily nasal irrigation for the treatment of pediatric chronic rhinosinusitis. Laryngoscope 121(9):1989-2000. https:/doi.org/10.1002/lary.21923

10. Ramadan HH, Terrell AM (2010) Balloon catheter sinuplasty and adenoidectomy in children with chronic rhinosinusitis. Ann Otol Rhinol Laryngol 119(9):578-582. https://doi.org/10.1177/000348941011900902

11. Rudnick EF, Mitchell RB (2007) Long-term improvements in quality-of-life after surgical therapy for pediatric sinonasal disease. Otolaryngol Head Neck Surg 137(6):873-877. https://doi.org/10.1016/j.otohns.2007.08.006

12. Kilaikode S, Shukla PJ, Phull G, Jackson JH, Prue DC, Martinez C, Scheffey K, Pillai DK (2017) Sino-Nasal 5 Questionnaire is associated with poor asthma control in children with asthma. Children 4(7):54

13. Ni JS, Kompelli AR, Nguyen SA, Schlosser RJ, Clemmens C, Soler ZM (2018) The Sinus and Nasal Quality of Life Survey (SN-5) in the management of pediatric chronic rhinosinusitis: a systematic review and meta-analysis. Int J Pediatr Otorhinolaryngol 111:162-169. https://doi.org/10.1016/j.ijporl.2018.06.010

14. Streiner DL, Norman GR (1995) Health measurement scales: a practical guide to their development and use. Oxford Medical Publications, Oxford

15. Guillemin F, Bombardier C, Beaton D (1993) Cross-cultural adaptation of healthrelated quality of life measures: literature review and proposed guidelines. J Clin Epidemiol 46(12):1417-1432. https:/doi.org/10.1016/0895-4356(93)90142-N

16. Ruperto N, Ravelli A, Pistorio A, Malattia C, Cavuto S, Gado-West L, Tortorelli A, Landgraf JM, Singh G, Martini A, Paediatric Rheumatology International Trials Organisation (2001) Cross-cultural adaptation and psychometric evaluation of the Childhood Health Assessment Questionnaire (CHAQ) and the Child Health Questionnaire (CHQ) in 32 countries. Review of the general methodology. Clin Exp Rheumatol 19:S1-S9

17. Uchoa PR, Bezerra TF, Lima ÉD, Fornazieri MA, Pinna FR, Sperandio FA, Voegels RL (2016) Cross-cultural adaptation and validation of the Sinus and Nasal Quality of Life Survey (SN-5) into Brazilian Portuguese. Braz J Otorhinolaryngol 82(6):636-642. https://doi.org/10.1016/j.bjorl.2015.11.013

18. Gliklich RE, Hilinski JM (1995) Longitudinal sensitivity of generic and specific health measures in chronic sinusitis. Qual Life Res 4(1):27-32. https://doi. org/10.1007/BF00434380

19. Calvo-Henríquez C, Valencia-Blanco B, Boronat-Catalá B, Maza-Solano J, DíazAnadón Á, Kahn S, Moure-Gonzalez JD, Faraldo-García A, MartinezCapoccioni G (2020) Cross-cultural adaptation of the sinus and nasal quality of life survey (SN-5) to Spanish. Int J Pediatr Otorhinolaryngol 139:110425. https://doi.org/10.1016/j.jporl.2020.110425

\section{Publisher's Note}

Springer Nature remains neutral with regard to jurisdictional claims in published maps and institutional affiliations. 